\section{Antihistamínicos en el tratamiento de la urticaria en México}

\section{RESUMEN}

Existen cuatro tipos de receptores histaminérgicos. Los síntomas de alergia, especialmente rinoconjuntivitis alérgica y urticaria, son principalmente causados por activación del receptor $\mathrm{H} 1$; por ende, los antihistamínicos $\mathrm{H} 1$ orales (anti-H1) forman parte integral del tratamiento de estas enfermedades. Los antihistamínicos son agonistas inversos, porque estabilizan la forma inactiva del receptor. Los antihistamínicos H1 de primera generación producen efectos adversos por varios mecanismos: sedación (fijación a receptores $\mathrm{H} 1$ cerebrales), boca seca, retención urinaria, aumento de peso (baja selectividad: estimulación de los receptores de serotonina, muscarina y alfa-adrenérgicos) e interacciones medicamentosas (con sustrato de citocromo P450-3A4). Los antihistamínicos $\mathrm{H} 1$ de segunda generación son generalmente más seguros. Las nuevas guías de tratamiento de la rinitis alérgica y urticaria recomiendan como manejo de primera intención a los antihistamínicos H1 de segunda generación. En urticaria se recomienda hasta cuadruplicar su dosis en caso necesario. El aumento de la eficacia en el control de la urticaria con cuádruple dosis, sin que se afecte la seguridad, se ha documentado para bilastina, desloratadina y levocetirizina (rupatadina). Respecto de ebastina y fexofenadina, hasta ahora, sólo se comprobó la seguridad de cuádruple dosis. Una rigurosa excepción son astemizol y terfenadina, que a concentraciones séricas elevadas pueden causar taquicardia ventricular. No se recomiendan los antihistamínicos $\mathrm{H} 1$ de primera generación y aumentar su dosis no es seguro.

Palabras clave: antihistamínicos de primera generación, antihistamínicos de segunda generación, urticaria, rinitis alérgica, sedación, citocromo P450.

\section{Antihistamines for the treatment of urticaria in Mexico}

\begin{abstract}
There are four types of histamine receptors. Allergic symptoms, especially those in rhinoconjunctivitis and urticaria, are mainly caused by activation of histamine receptor $1(\mathrm{H} 1)$. Consequently, oral $\mathrm{H} 1$-antihistamines form and integral part of the treatment of these diseases. Antihistamines are inverse agonists that stabilize the non-active configuration of the histamine receptor. First generation $\mathrm{H} 1$-antihistamines cause a variety of adverse effects via several mechanisms: sedation (accumulation in the central nervous system), dry mouth, urinary retention, weight gain (low selectivity: stimulation of serotonin/muscarinic/alpha-adrenergic receptors) and drug interactions (substrate of CYP450-3A4). Generally second generation $\mathrm{H} 1$-antihistamines have a better safety profile. New guidelines on allergic rhinitis and urticaria recommend second genera-
\end{abstract}

Désirée Larenas-Linnemann ${ }^{1}$

Mario Sánchez-Borges ${ }^{2}$

Blanca del Río-Navarro ${ }^{3}$

María de Lourdes Alonzo-Romero Pareyón ${ }^{4}$

César Alfonso Maldonado-García ${ }^{4}$

Enrique Mendoza-López ${ }^{5}$

José Antonio Ortega-Martell ${ }^{6}$

Juan José Sienra-Monge ${ }^{7}$

Miguel Alejandro Medina-Ávalos ${ }^{8}$

María Isabel Rojo-Gutiérrez ${ }^{9}$

Angélica María Beirana-Palencia ${ }^{10}$

Jorge Bernardo Vargas-Correa ${ }^{11}$

Carlos Báez-Loyola ${ }^{12}$

Ruth Ivonne Mireya Ramírez-Segura ${ }^{13}$

María Graciela Guzmán-Perea ${ }^{14}$

${ }^{1}$ Clínica de Alergia, Asma y Pediatría del Sur, Hospital Médica Sur, México, DF.

2 Departamento de Alergia e Inmunología Clínica, Centro Médico-Docente La Trinidad, Caracas, Venezuela.

${ }^{3}$ Servicio de Alergia, Hospital Infantil de México Federico Gómez, Secretaría de Salud, México, DF.

${ }^{4}$ Centro Dermatológico Dr. Ladislao de la Pascua, Secretaría de Salud, México, DF.

${ }^{5}$ Sistema Tec Salud, Hospital San José, Monterrey, Nuevo León, México.

${ }^{6}$ Universidad Autónoma del Estado de Hidalgo, Pachuca, Hidalgo, México.

${ }^{7}$ Dirección de Investigación, Hospital Infantil de México Federico Gómez, Secretaría de Salud, México, DF. ${ }^{8}$ Servicio de Alergia, ISSSSTE Veracruz, Veracruz, México.

${ }^{9}$ Servicio de Alergia e Inmunología Clínica, Hospital Juárez de México, Secretaría de Salud, México, DF.

${ }^{10}$ Dermatóloga y dermatóloga pediatra, México, DF.

${ }^{11}$ Servicio de Medicina Interna, Hospital Regional Mérida, Instituto de Seguridad y Servicios Sociales de los Trabajadores del Estado, Mérida, Yucatán, México. 12 Unidad de Asma y Alergia, Hospital Médica Sur, México, DF.

${ }^{13}$ Sociedad Mexicana de Pediatría, México, DF.

${ }^{14}$ Clínica de Dermatología, Hospital Ángeles del Pedregal, México, DF.

Recibido: 14 de enero 2015

Aceptado: 15 de abril 2015

Correspondencia: Dra. Désirée Larenas

Linnemann

Hospital Médica Sur, Torre 2, consultorio 602

Puente de Piedra 150

14050 México, DF

marlar1@prodigy.net.mx

Este artículo debe citarse como

Larenas-Linnemann D, Sánchez-Borges $M$, Del Río-Navarro B, Alonzo-Romero Pareyón ML y col. Antihistamínicos en el tratamiento de la urticaria en México. Revista Alergia México 2015;62:157-174. 
tion $\mathrm{H} 1$-antihistamines as first line drugs, with -if necessary- four-times updosing to obtain control in urticaria. The enhanced efficacy of quadruple doses in urticaria, while maintaining a good safety profile, has been shown for bilastine, desloratadine and levocetirizine (rupatadine). For ebastine and fexofenadine only the safety of quadruple doses has been shown till now. Extreme precaution should be taken with astemizol and terfenadine that never should be up-dosed, as high serum concentrations can cause potentially fatal ventricular tachycardia. First generation antihistamines are not recommended as first line treatment and updosing is not safe.

Key words: first generation antihistamines, second generation antihistamines, urticaria, allergic rhinitis, sedation, cytochrome P450.

\section{ANTECEDENTES}

Al igual que en otras áreas de la medicina, recientemente se publicaron varias guías para el tratamiento de enfermedades en el área de la Alergología. Dos de ellas son la guía ARIA (por sus siglas en inglés de Rinitis Alérgica y su Impacto en el Asma) ${ }^{1}$ y la guía del diagnóstico y tratamiento de urticaria, que nació de una colaboración de la Academia de Alergia e Inmunología Clínica Europea (EAACI) y la Organización Mundial de Alergia (WAO). ${ }^{2}$ En 2014 se publicó en México una transculturización de la guía ARIA internacional, ARIA México $2014^{3}$ y unos meses después, una adaptación para México de lineamientos para el diagnóstico y tratamiento de la urticaria. ${ }^{4}$ Para el desarrollo de ambas guías mexicanas sus autores siguieron estrictamente las herramientas reconocidas internacionalmente para adaptación y transculturización de guías de manejo clínico: SCOPE, AGREE-II y ADAPTE. ${ }^{5}$ Las guías mexicanas fueron el resultado de la colaboración de expertos de múltiples organizaciones de especialistas y ambas guías cuentan con el aval de la Academia Nacional de la Medicina.

Los antihistamínicos $\mathrm{H} 1$ orales son medicamentos básicos para el tratamiento de ambas enfermedades: rinitis alérgica y urticaria. En nuestro país aún abunda la administración de antihistamínicos $\mathrm{H} 1$ orales de primera generación. Sin embargo, en la guía para el tratamiento de la rinitis alérgica, ARIA México 2014, y en la guía mexicana de urticaria los expertos insisten en la administración de antihistamínicos de segunda generación como base del tratamiento médico. Varios expertos que colaboraron en las guías revisan en este artículo los detalles alrededor de este grupo de medicamentos: los antihistamínicos $\mathrm{H} 1$ orales. Este documento inicia con una revisión de los receptores histaminérgicos, seguido por la interacción entre los antihistamínicos y su receptor $\mathrm{H} 1$, antes de pasar a la parte clínica que se enfoca en la administración de antihistamínicos en urticaria. Cuadros con las recomendaciones oficiales de antihistamínicos H1 en México, al igual que unos párrafos acerca de su prescripción en mujeres embarazadas y amamantando, complementan la revisión.

\section{MATERIAL Y MÉTODO}

Para la primera parte de este escrito se buscaron artículos de revisión publicados los últimos cinco años, escritos por autoridades en el área, tanto clínicos como farmacológicos. De esta forma las secciones de histamina, los receptores 
histaminérgicos, el mecanismo de acción de los antihistamínicos y los antihistamínicos de primera y segunda generación es un resumen de los puntos más importantes en estas áreas para poder entender cómo administrar los antihistamínicos en el tratamiento de urticaria. Para la segunda parte acerca de la administración de antihistamínicos $\mathrm{H} 1$ orales para el tratamiento de la urticaria y su aumento de dosis se buscaron artículos originales de los últimos 15 años con los términos de búsqueda: 'urticaria' AND 'antihistamine*', 'urticaria' AND '[los nombres individuales de los antihistamínicos de primera y segunda generación], todo esto con los filtros de 'human', 'clinical trial' OR 'controlled clinical trial' OR 'clinical trial phase I-IV' OR 'randomized controlled trial'. Para la revisión de los efectos colaterales de los antihistamínicos se buscó de la misma manera, sustituyendo 'urticaria' por 'sedation' OR 'side-effect*' OR 'sleepiness' OR 'brain' OR 'cerebral' OR 'central nervous system'. Para la última parte de esta revisión y las tablas específicas mexicanas se consultaron los documentos oficiales de información para prescribir actualizados hasta junio 2014 y la información oficial de la Dirección de Alimentos y Fármacos de Estados Unidos acerca de las categorías de medicamentos para administración durante el embarazo y específicamente sus recomendaciones para antihistamínicos $\mathrm{H} 1$ orales.

\section{Histamina y sus receptores}

En urticaria, la mayor parte de los síntomas son causados por histamina. Al degranular la célula cebada se libera gran cantidad de histamina, que al fijarse a sus receptores genera los síntomas clásicos de la urticaria. Después de degranularse, la célula cebada nuevamente Ilena sus gránulos de histamina y así puede volver a liberar más. Existen cuatro receptores de histamina en el cuerpo, $\mathrm{H} 1-\mathrm{H} 4$, presentes en la membrana celular de diferentes células. El receptor $\mathrm{H} 1$ está implicado en el prurito, eritema, edema y el proceso inflamatorio en urticaria. Más detalles acerca de los receptores histaminérgicos se encuentran en el Cuadro 1.6-10

\section{Antihistamínicos: modo de acción}

Los receptores de histamina no son moléculas rígidas. Son estructuras transmembrana que continuamente cambian de una configuración (activa) a otra configuración (no activa). Mientras estén en su configuración activa, estimulan otras proteínas dentro de la célula, trasmitiendo su señal de activación de ciertas funciones intracelulares. La histamina fija el receptor en su estado activo y los antihistamínicos fijan el receptor en su estado no activo. Por ello se llaman agonistas inversos, porque reducen el número de receptores en estado activo. El antiguo término de antagonista no es correcto (Figura 1).

\section{Antihistamínicos $\mathrm{H} 1$ orales de primera y segunda generación}

Existen dos grupos de antihistamínicos $\mathrm{H} 1$, los de primera y los de segunda generación. Los antihistamínicos $\mathrm{H} 1$ orales de segunda generación tienen características específicas que las diferencian de los de primera generación. Así, los antihistamínicos $\mathrm{H} 1$ de segunda generación tienen menos reacciones adversas que los de primera generación, lo que aumenta considerablemente su seguridad (Cuadro 2). Existen tres mecanismos principales mediante los cuales los antihistamínicos $\mathrm{H} 1$ de primera generación causan efectos adversos. En primer lugar carecen de selectividad para los receptores $\mathrm{H} 1$. La estimulación de receptores muscarínicos, serotoninérgicos y alfa-adrenérgicos por los antihistamínicos $\mathrm{H} 1$ de primera generación resulta en una gama de reacciones adversas. Además, no son sustratos de la glicoproteína pG (G-pG), una proteína transportadora que facilita la salida de los antihistamínicos de segunda generación del sistema nervioso central; en consecuencia, los antihistamínicos $\mathrm{H} 1$ de primera generación se fijan ampliamente a receptores en la paracor- 
Cuadro 1. Receptores de histamina: localidad y funciones

\begin{tabular}{|c|c|c|c|c|}
\hline $\begin{array}{l}\text { Tipo de } \\
\text { receptor }\end{array}$ & $\begin{array}{l}\text { Presente en la membra- } \\
\text { na celular de }\end{array}$ & Algunas de sus funciones & $\begin{array}{c}\text { Ejemplos } \\
\text { (orden alfabético) }\end{array}$ & Acción \\
\hline Receptor H1 & $\begin{array}{l}\text { Sistema nervioso central, } \\
\text { músculo liso (vascular, } \\
\text { respiratorio, gastroin- } \\
\text { testinal), sistema car- } \\
\text { diovascular, neutrófilos, } \\
\text { eosinófilos, monocitos, } \\
\text { macrófagos, células den- } \\
\text { dríticas, linfocitos B y T, } \\
\text { células endoteliales y } \\
\text { epiteliales }\end{array}$ & $\begin{array}{l}\text { Activación de neuronas } \\
\text { sensoriales: prurito, eri- } \\
\text { tema. Extravasación de } \\
\text { líquido vascular: edema. } \\
\text { Aumento de la infla- } \\
\text { mación: mejora la pre- } \\
\text { sentación de antígenos, } \\
\text { expresión de citocinas } \\
\text { proinflamatorias, mo- } \\
\text { léculas de adhesión y } \\
\text { quimotaxis. } \\
\text { Bronquios: broncocons- } \\
\text { tricción } \\
\text { Sistema nervioso central: } \\
\text { estado de alerta, reduce } \\
\text { el apetito }\end{array}$ & $\begin{array}{l}\text { Cetirizina, clorfeniramina, } \\
\text { desloratadina, difenhi- } \\
\text { dramina, fexofenadina, } \\
\text { hidroxizina, levocetiri- } \\
\text { zina, loratadina y } 40 \text { más }\end{array}$ & $\begin{array}{l}\text { Reduce la inflamación } \\
\text { alérgica; según su con- } \\
\text { centración: reduce la } \\
\text { activación de la célula } \\
\text { cebada y la liberación } \\
\text { de histamina. } \\
\text { Sistema nervioso central: } \\
\text { reduce el estado de vi- } \\
\text { gilia, la memoria, causa } \\
\text { sedación, aumento del } \\
\text { apetito }\end{array}$ \\
\hline Receptor $\mathrm{H} 2$ & $\begin{array}{l}\text { Células parietales gástri- } \\
\text { cas, músculo liso, sis- } \\
\text { tema nervioso central, } \\
\text { sistema cardiovascular, } \\
\text { neutrófilos, eosinófilos, } \\
\text { monocitos, macrófagos, } \\
\text { células dendríticas, lin- } \\
\text { focitos B y T, células } \\
\text { endoteliales y epiteliales }\end{array}$ & $\begin{array}{l}\text { Aumento de la liberación } \\
\text { de ácido gástrico. Acción } \\
\text { proinflamatoria, pero } \\
\text { también autorregulación } \\
\text { con reducción de la libe- } \\
\text { ración de más histamina. } \\
\text { Reduce la inflamación } \\
\text { inducida por microorga- } \\
\text { nismos }^{7}\end{array}$ & $\begin{array}{l}\text { Cimetidina, famotidina, } \\
\text { nizatidina, ranitidina, }\end{array}$ & Antiácido \\
\hline Receptor H3 & $\begin{array}{l}\text { Sistema nervioso central } \\
\text { y neuronas periféricas, } \\
\text { sistema cardiovascular, } \\
\text { pulmones, monocitos, } \\
\text { eosinófilos, células en- } \\
\text { doteliales }\end{array}$ & Neurotrasmisión & $\begin{array}{l}\text { No hay sustancias apro- } \\
\text { badas }\end{array}$ & $\begin{array}{l}\text { Moléculas en investiga- } \\
\text { ción para el tratamiento } \\
\text { de rinitis alérgica y enfer- } \\
\text { medades psiquiátricas }^{8}\end{array}$ \\
\hline Receptor H4 & $\begin{array}{l}\text { Neutrófilos, eosinófi- } \\
\text { los, monocitos, células } \\
\text { dendríticas, células de } \\
\text { Langerhans, linfocitos T, } \\
\text { basófilos, células ceba- } \\
\text { das, fibroblastos, médula } \\
\text { ósea, células endocri- } \\
\text { nas y sistema nervioso } \\
\text { central }\end{array}$ & $\begin{array}{l}\text { Inmunomodulación. }{ }^{9} \\
\text { Acción proinflamatoria } \\
\text { (quimiotaxis eosinófilos } \\
\text { y linfocitos), pero tam- } \\
\text { bién inmunorregulatoria: } \\
\text { reduce la inflamación } \\
\text { bronquial (ratón). Estimu- } \\
\text { lación de los receptores } \\
\text { de prurito }^{10}\end{array}$ & $\begin{array}{l}\text { No hay sustancias apro- } \\
\text { badas }\end{array}$ & $\begin{array}{l}\text { Moléculas en investiga- } \\
\text { ción para el tratamien- } \\
\text { to de rinitis alérgica y } \\
\text { prurito }\end{array}$ \\
\hline
\end{tabular}

Adaptado de la referencia 16.

teza causando sedación. Por último, son sustrato para enzimas del complejo de citocromo P450 en el hígado, lo que resulta en interacciones medicamentosas con aumento de las concentraciones plasmáticas cuando se coadministran con ketokonazol, macrólidos o cimetidina, por ejemplo. No conocemos a detalle las características farmacocinéticas y farmacodinámicas de los antihistamínicos $\mathrm{H} 1$ orales de primera generación, debido a que obtuvieron su registro hace varias décadas. Por el contrario, las características farmacocinéticas y farmacodinámicas 

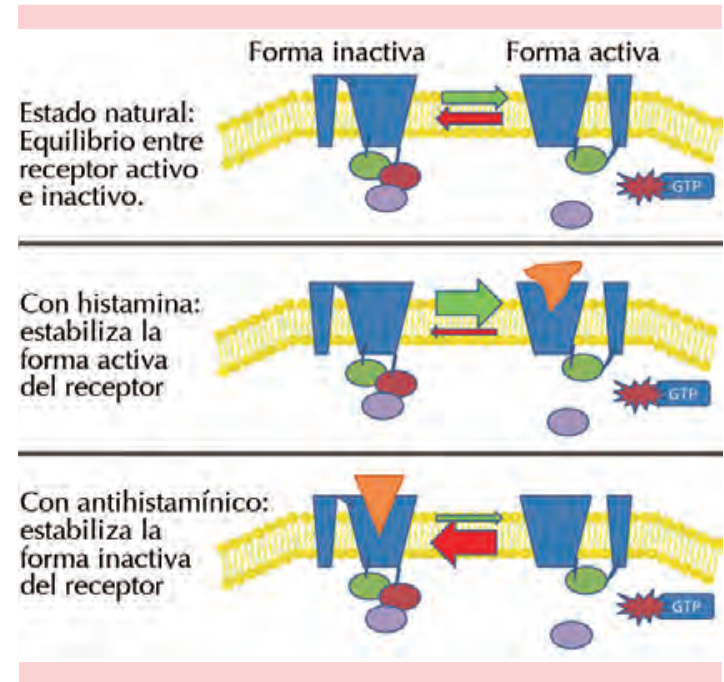

Figura 1. Mecanismo de acción de los antihistamínicos $\mathrm{H} 1$.

de los antihistamínicos $\mathrm{H} 1$ orales de segunda generación se han documentado a detalle. De algunos antihistamínicos $\mathrm{H} 1$ de primera y pocos antihistamínicos $\mathrm{H} 1$ de segunda generación, especialmente terfenadina y astemizol, se ha documentado un cuarto mecanismo de efectos adversos: en dosis elevadas pueden interferir con el funcionamiento de los canales Kv11.1 de potasio a nivel cardiaco, causando alargamiento del intervalo QTc y taquicardia ventricular potencialmente mortal, también conocida como 'torsade des pointes'. ${ }^{11}$

Conclusión. Los antihistamínicos de segunda generación son más selectivos $\mathrm{H} 1$, tienen mejor perfil de seguridad y causan menor o nula sedación, a excepción de astemizol y terfendina (prolongación del intervalo QTC) y ketotifeno (sedante).

\section{Antihistamínicos $\mathrm{H} 1$ orales de primera generación para el tratamiento de la urticaria}

Aunque los antihistamínicos $\mathrm{H} 1$ orales de primera generación se consideran históricamente

Cuadro 2. Características de antihistamínicos H1 orales de primera y segunda generación

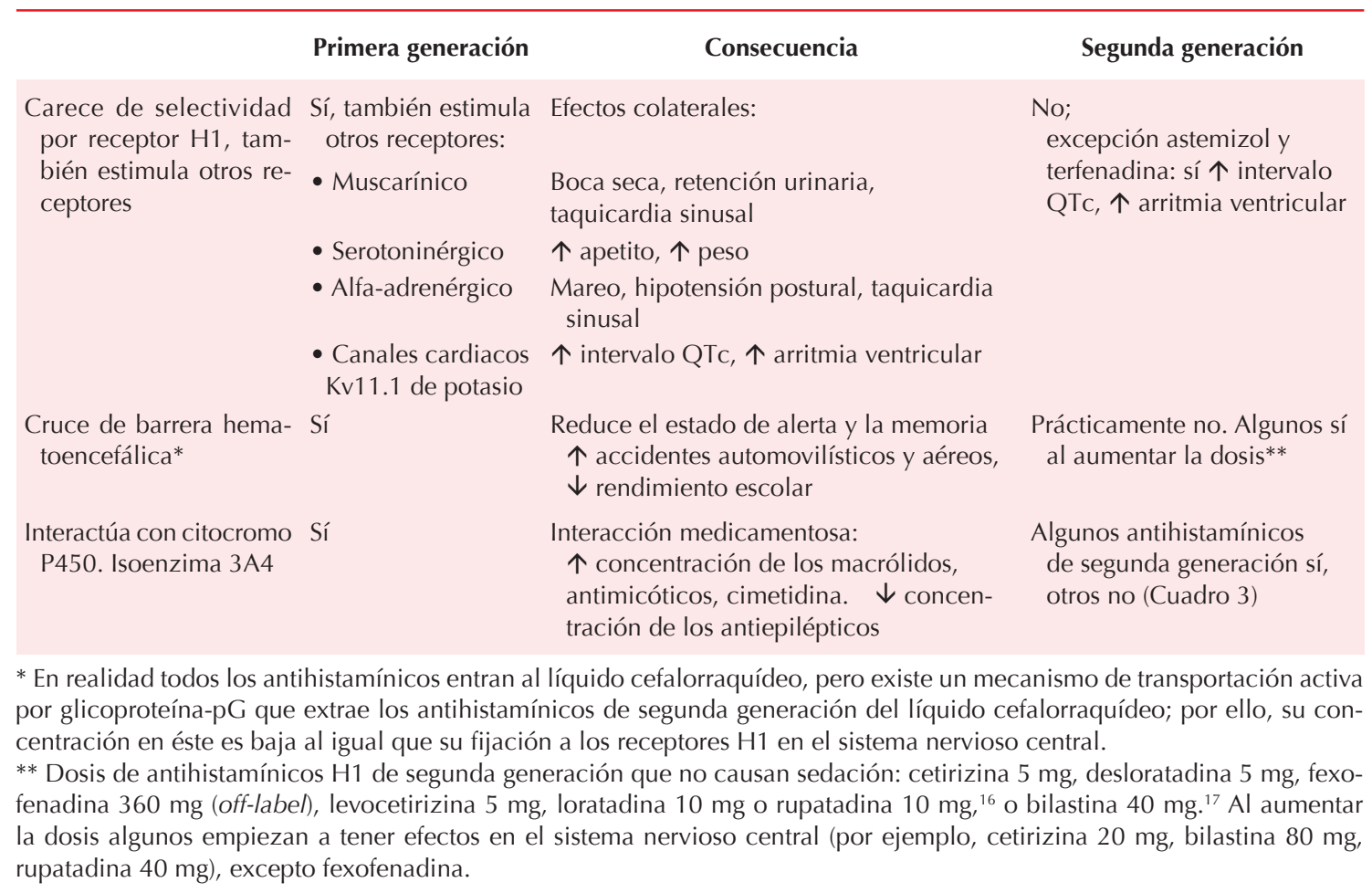


medicamentos base para el tratamiento de la urticaria, existen relativamente pocos estudios clínicos que avalen esta indicación. ${ }^{12}$ Además, la mayor parte de los estudios se realizaron hace años o en ambientes con restricción de recursos. En consecuencia, no cumplen con los estándares que hoy día se piden a la investigación científica, como los lineamientos de CONSORT, enfocados al reporte transparente de estudios clínicos, ${ }^{13}$ y GRADE, enfocado al reporte sin sesgo y de buena calidad. ${ }^{14}$

Aunque la larga experiencia clínica aunada a algunos estudios clínicos ${ }^{15}$ no dejan duda en cuanto a su eficacia, su mayor inconveniencia son los efectos colaterales (Cuadros 2 y 3). ${ }^{16,17}$ Especialmente el extenso metabolismo en el hígado resulta en interacciones medicamentosas, que pueden aumentar las concentraciones séricas de ciertos antihistamínicos, lo que finalmente puede causar alargamiento del intervalo QTC y arritmias (Cuadro 3).

Además, la reducción del estado de alerta y de la velocidad de reacción ${ }^{18}$ son factores importantes desde el punto de vista de la seguridad, sobre todo porque es frecuente que el paciente no se da cuenta de estos efectos. ${ }^{19}$ De tal manera, se ha relacionado la ingestión de antihistamínicos H1 de primera generación con accidentes automovilísticos y aéreos fatales. ${ }^{20}$ Una dosis única de hidroxizina de $50 \mathrm{mg}$ combinada con alcohol (un consumo social) afectó significativamente el rendimiento de voluntarios sanos en una prueba de manejo y pruebas sencillas cognitivas. ${ }^{21}$ Otros estudios mostraron claramente cómo la administración de antihistamínicos $\mathrm{H} 1$ orales de primera generación afecta el rendimiento escolar en niños ${ }^{22}$ y de adolescentes en tiempo de exámenes finales. ${ }^{23}$

Por su efecto sedante, algunos médicos recomiendan la administración de antihistamínicos H1 orales sedantes de primera generación en las noches. Sin embargo, se demostró que la administración de una dosis única de un antihistamínico $\mathrm{H} 1$ sedante altera el patrón del sueño, afectando especialmente la fase REM, que es esencial para la memoria. ${ }^{11,24}$ Además, se documentó claramente un efecto sedante aún la mañana siguiente a la administración de difenhidramina. ${ }^{25}$ Recientemente se demostraron estos efectos en ratas también con antihistamínicos H1 orales poco sedantes de segunda generación, aunque en menor grado. ${ }^{26}$

La creencia de que los antihistamínicos sedantes tienen mayor eficacia en el control de la urticaria no se confirmó en un estudio doble ciego con distribución al azar de 24 pacientes con urticaria crónica espontánea de difícil control. Los investigadores mostraron que el tratamiento combinado con levocetirizina en la mañana e hidroxizina en la noche aumentó la somnolencia diurna en los pacientes, sin mejorar la eficacia del tratamiento en comparación con la monoterapia de levocetirizina a dosis altas. ${ }^{27}$

Conclusión. Para el tratamiento de la urticaria no se recomiendan los antihistamínicos $\mathrm{H} 1$ orales, sedantes de primera generación, en adultos ni en niños por su perfil de seguridad poco favorable, su relación con accidentes de tránsito y con reducción del rendimiento. Además, su eficacia en urticaria crónica espontánea no fue mejor que la de los antihistamínicos de segunda generación en dosis altas.

\section{Antihistamínicos $\mathrm{H} 1$ orales de segunda generación para el tratamiento de urticaria}

Los antihistamínicos $\mathrm{H} 1$ de segunda generación son los medicamentos de primera elección para el tratamiento de urticaria (azelastina, bilastina, cetirizina, desloratadina, ebastina, fexofenadina, levocetirizina, loratadina, mizolastina y rupatadina).,28 Disponemos de decenas de estudios clínicos con distribución al azar que muestran 
Cuadro 3. Antihistamínicos y su interacción con enzimas del complejo citocromo P450-3A4

\begin{tabular}{|c|c|c|c|}
\hline Sustancia activa & Texto en la información para prescribir & Metaboliza & QTc \\
\hline \multicolumn{4}{|c|}{ Sin interacción } \\
\hline Fexofenadina (Allegra ${ }^{\circledR}$ ) & Se metaboliza de manera insignificante & 0 & 0 \\
\hline $\begin{array}{l}\text { Bilastina } \\
\left.\text { (Blaxitec }^{\circledR}\right)\end{array}$ & $\begin{array}{l}\text { Bilastina no es metabolizada en humanos. La administración concomitante } \\
\text { de bilastina y ketoconazol o eritromicina aumentó el área bajo la curva de } \\
\text { bilastina dos veces y la concentración máxima dos a tres veces, por la inte- } \\
\text { racción con transportadores intestinales de excreción, porque bilastina es } \\
\text { sustrato de la P-GP. Estos cambios no parecen afectar al perfil de seguridad } \\
\text { de bilastina, ketoconazol o eritromicina. No se requiere ajustar la dosis en } \\
\text { pacientes con insuficiencia hepática }\end{array}$ & 0 & 0 \\
\hline $\begin{array}{l}\text { Epinastina } \\
\left(\text { Flurinol }^{\circledR}\right)\end{array}$ & $\begin{array}{l}\text { Epinastina se elimina sin modificar por el riñón, por lo que no es de esperar } \\
\text { que interfiera con fármacos que son metabolizados por medio del sistema } \\
\text { enzimático citocromo P450 (como ketoconazol y eritromicina) }\end{array}$ & 0 & 0 \\
\hline $\begin{array}{l}\text { Levocetirizina } \\
\left(\text { Xuzal }^{\circledR}\right)\end{array}$ & $\begin{array}{l}\text { La tasa metabólica de la levocetirizina en humanos es menor a } 14 \% \text {. Debido } \\
\text { a su escaso metabolismo y a la ausencia de potencial de inhibición meta- } \\
\text { bólica, la interacción de la levocetirizina con otros fármacos y viceversa } \\
\text { es muy improbable }\end{array}$ & 0 & 0 \\
\hline $\begin{array}{l}\text { Desloratadina } \\
\left(\text { Aviant }^{\circledR}, \text { Azomyr }^{\circledR}\right)\end{array}$ & $\begin{array}{l}\text { Es metabolizada en el hígado, pero no inhibe CYP3A4 ni CYP2D6. No es } \\
\text { sustrato ni inhibidor de la glucoproteína P. No se ha demostrado interacción } \\
\text { farmacológica con ketoconazol, eritromicina o cimetidina }\end{array}$ & 0 & 0 \\
\hline $\begin{array}{l}\text { Cetirizina } \\
\left(\text { Virlix }^{\circledR}, Z \text { Zrtec }^{\circledR}\right)\end{array}$ & $\begin{array}{l}\text { Los estudios con cetirizina y cimetidina, glipizida, diazepam y pseudoefe- } \\
\text { drina revelaron que no hay evidencias de interacciones farmacodinámicas } \\
\text { adversas. Los estudios con cetirizina y azitromicina, eritromicina, ketoco- } \\
\text { nazol, teofilina y pseudoefedrina demostraron que no hay evidencias de } \\
\text { interacciones clínicas adversas. En pacientes con disfunción hepática o } \\
\text { disfunción renal se recomienda ajustar la dosis }\end{array}$ & + & 0 \\
\hline \multicolumn{4}{|c|}{ Con interacción } \\
\hline Rupatadina & $\begin{array}{l}\text { Sí interactúa con citocromo P450, isoenzima CYP3A4. Se recomienda tener } \\
\text { precaución con la administración concomitante con ketoconazol, eritro- } \\
\text { micina u otros inhibidores del CYP3A4, estatinas. Incrementa los efectos } \\
\text { del alcohol a dosis de } 20 \mathrm{mg} \text {, no a dosis de } 10 \mathrm{mg} \text {. No puede excluirse la } \\
\text { interacción con depresores del sistema nervioso central }\end{array}$ & ++ & 0 \\
\hline Loratadina & $\begin{array}{l}\text { Ampliamente metabolizada en el hígado. Con la administración concomi- } \\
\text { tante con ketoconazol, eritromicina y cimetidina se ha reportado aumento } \\
\text { en las concentraciones de loratadina }\end{array}$ & +++ & 0 \\
\hline Ebastina & $\begin{array}{l}\text { Es metabolizada a través del citocromo P450 CYP3A4. Insuficiencia hepática } \\
\text { severa, prolongación QT, hipocaliemia. Concomitancia con fármacos que } \\
\text { incrementen el intervalo QT o inhibidores de CYP450, como antifúngicos } \\
\text { azólicos y antibióticos macrólidos. No administrar junto con rifampicina }\end{array}$ & +++ & ++ \\
\hline Terfenadina & Ya no está disponible en el mercado mexicano & +++ & +++ \\
\hline Astemizol & $\begin{array}{l}\text { Extenso metabolismo de primer paso. Después de la administración prolon- } \\
\text { gada de } 10 \mathrm{mg} \text { al día, la vida media de eliminación fue de } 18 \text { a } 20 \text { días. Con } \\
\text { administración de } 20-30 \mathrm{mg} / \text { día se ha reportado: paro cardiaco irreversible, } \\
\text { prolongación del segmento QT, taquicardia ventricular polimórfica y otras } \\
\text { arritmias ventriculares. No se recomienda su administración conjunta con } \\
\text { itraconazol, ketoconazol, eritromicina }\end{array}$ & +++ & +++ \\
\hline $\begin{array}{l}\text { Antihistamínico de pri- } \\
\text { mera generación }\end{array}$ & Todos tienen extenso metabolismo de primer paso & +++ & $+/++{ }^{16}$ \\
\hline
\end{tabular}


su seguridad y eficacia en pacientes con urticaria, ${ }^{28-30}$ lo que suma alta calidad de evidencia.

En el Cuadro 4 se mencionan las dosis habituales diarias -según documentación regulatoria mexicana- de los antihistamínicos de segunda generación, que resultaron eficaces en pacientes con urticaria.

Se comparó la eficacia en el tratamiento de urticaria de algunos antihistamínicos $\mathrm{H} 1$ de segunda generación a dosis habituales de manera directa en estudios clínicos con diseño doble-ciego: cetirizina $10 \mathrm{mg}$ fue superior a fexofenadina 180 mg, ${ }^{31}$ levocetirizina $5 \mathrm{mg}$ fue superior a desloratadina $5 \mathrm{mg}^{32}$ y bilastina $20 \mathrm{mg}$ fue igual de eficaz que levocetirizina $5 \mathrm{mg} .{ }^{33}$ También se compararon los antihistamínicos $\mathrm{H} 1$ de segunda generación de manera indirecta en su capacidad de supresión de la roncha inducida por histamina, mostrando resultados semejantes a los de arriba, pero no se sabe a ciencia cierta cómo se deben interpretar estos análisis en términos clínicos. ${ }^{34-37}$

De algunos antihistamínicos $\mathrm{H} 1$ de segunda generación existen datos de su eficacia y seguridad en niños a partir de seis meses de edad con urticaria crónica idiopática (Cuadro 4). ${ }^{38}$

Conclusión. Los antihistamínicos H1 de segunda generación en dosis habituales son los medicamentos de primera elección para el tratamiento de la urticaria (fuerte recomendación). Algunos son autorizados en niños a partir de seis meses de edad (recomendación débil). Varían en su perfil de eficacia y seguridad.

\section{Multiplicación de la dosis habitual de antihistamínicos de segunda generación}

De algunos antihistamínicos orales de segunda generación se demostró mayor eficacia para el control de la urticaria crónica espontánea con aumento de la dosis, sin que se viera afectada la tolerabilidad..$^{39}$ La doble dosis $-2 \times 10 \mathrm{mg}$ - fue mejor que la monodosis de cetirizina ${ }^{40} y$ ebastina. ${ }^{41}$ Los investigadores mostraron aumento de la eficacia con dosificación hasta cuatro veces la dosis habitual recomendada de bilastina (80 $\mathrm{mg}$ ) en urticaria al frío, ${ }^{42}$ al igual que de levocetirizina $^{43}(20 \mathrm{mg})$ y desloratadina $(20 \mathrm{mg}) .{ }^{44} \mathrm{En}$ cuanto al efecto benéfico al aumentar la dosis de rupatadina de 10 a 20 mg en urticaria crónica se mostró una tendencia de mejor control con la dosis más alta; sin embargo, no se pudo demostrar una diferencia estadísticamente significativa entre ambos grupos tratados con activo. Asimismo, el aumento de eficacia de rupatadina $40 \mathrm{mg}$ comparado con dosis menores sí se documentó con claridad previamente en experimentos con adultos sanos ex vivo. ${ }^{45,46}$

Un estudio de diseño doble-ciego y cruzado mostró mayor eficacia de levocetirizina a cuádruple dosis contra desloratadina a cuádruple dosis. Estos datos aún limitados nos permiten emitir una recomendación débil (sugerencia) para prescribir hasta cuádruple dosis de estos tres antihistamínicos. ${ }^{47}$ Sin embargo, la recomendación respecto de fexofenadina es negativa y fuerte: no se obtiene mayor eficacia al aumentar su dosis arriba de $180 \mathrm{mg} \cdot{ }^{16}$

Conclusión. En pacientes con urticaria crónica espontánea sin mejoría con dosis habituales de antihistamínicos $\mathrm{H}_{1}$ se puede administrar por tiempo limitado hasta cuatro veces la dosis habitual únicamente de levocetirizina, desloratadina o bilastina y en ocasiones rupatadina (recomendación débil), pero no de otros antihistamínicos (recomendación fuerte negativa).

\section{Antihistamínicos y afectación de las funciones cognitivas}

Estudios recientes con medición de ocupación de receptores cerebrales $\mathrm{H} 1$ mediante tomografía por emisión de positrones mostraron en qué porción 
Cuadro 4. Antihistamínicos H1 de segunda generación: presentaciones y posología habitual recomendada

\begin{tabular}{|c|c|c|c|}
\hline & Formulación & Dosis diaria habitual adulto & Dosis diaria habitual pediátrica \\
\hline $\begin{array}{l}\text { Bilastina } \\
\left.\text { (Blaxitec }^{\circledR}\right)\end{array}$ & Tabl 20 mg & Adultos y niños > 12a: $20 \mathrm{mg}$ & $x$ \\
\hline $\begin{array}{l}\text { Cetirizina } \\
\left(\text { Virlix }^{\circledR}, \text { Zyrtec }^{\circledR}\right)\end{array}$ & $\begin{array}{l}\text { Tabl } 10 \mathrm{mg} \\
\text { Solución infantil: } 5 \mathrm{mg} / 5 \mathrm{~mL} \text {, } \\
\text { solución pediátrica: } 10 \mathrm{mg} / \mathrm{mL}\end{array}$ & Adultos y niños $>6$ años: $10 \mathrm{mg}$ & $\begin{array}{l}1-2 \text { años: } 2.5 \mathrm{mg} \text { bid } \\
\text { 2-6 años: } 2.5 \mathrm{mg} \text { bid } \\
\text { Dosis ponderal: } \\
0.2-0.3 \mathrm{mg} / \mathrm{kg} / \mathrm{día}\end{array}$ \\
\hline $\begin{array}{l}\text { Desloratadina } \\
\left(\text { Aviant }^{\circledR}, \text { Azomyr }^{\circledR},\right. \\
\left.\text { Deslibal }^{\circledR}\right)\end{array}$ & $\begin{array}{l}\text { Tabl } 5 \mathrm{mg} \\
\text { Jarabe y solución: } 2.5 \mathrm{mg} / 5 \mathrm{~mL}\end{array}$ & Adultos y niños > 12a: 5 mg & $\begin{array}{l}\text { 6-11 m: } 1 \mathrm{mg}(=2 \mathrm{~mL}) \\
\text { 12m-5a: } 1.25 \mathrm{mg}(2.5 \mathrm{~mL}) \\
\text { 6-11 años: } 2.5 \mathrm{mg}(5 \mathrm{~mL})\end{array}$ \\
\hline $\begin{array}{l}\text { Ebastina } \\
\left(\text { Evastel }^{\circledR},{ } \text { Evastel } Z^{\circledR},\right. \\
\left.\text { Pinavalt }{ }^{\circledR}\right)\end{array}$ & $\begin{array}{l}\text { Comp } 10 \mathrm{mg}, 20 \mathrm{mg}, \\
\mathrm{Z}=\text { obleas } 10,20 \mathrm{mg} \\
\text { Solución: } 5 \mathrm{mg} / 5 \mathrm{~mL}\end{array}$ & Adultos y >12a: $10 \mathrm{mg}, 20 \mathrm{mg}$ & 6-11 años: $5 \mathrm{mg}(5 \mathrm{~mL})$ \\
\hline Epinastina & $\begin{array}{l}\text { Tabl } 20 \text { mg, } \\
\text { Suspensión } 10 \mathrm{mg} / 5 \mathrm{~mL}\end{array}$ & Adultos y >12a: $20 \mathrm{mg}$ & $\begin{array}{l}\text { 6-10a: } 5 \mathrm{~mL} \\
\text { 10-12años: } 7.5 \mathrm{~mL} \\
0.4 \text { mg/kg/d (máx. } 20 \mathrm{mg} \text { ) }\end{array}$ \\
\hline $\begin{array}{l}\text { Fexofenadina } \\
\left.\text { (Allegra }^{\circledR}\right)\end{array}$ & $\begin{array}{l}\text { Tabl } 120 \mathrm{mg}, 180 \mathrm{mg} \\
\text { Comp } 30 \mathrm{mg} \\
\text { Suspensión } 30 \mathrm{mg} / 5 \mathrm{~mL}\end{array}$ & $\begin{array}{l}\text { Rinitis alérgica: } 120 \text { o } 180 \text { mg } \\
\text { Urticaria crónica idiopática: } \\
180 \mathrm{mg}\end{array}$ & $\begin{array}{l}\text { 6m-2años: } 15 \mathrm{mg}(2.5 \mathrm{~mL}) \\
\text { bid* } \\
\text { 2-11 años: } 30 \mathrm{mg}(5 \mathrm{~mL}) \text { bid } \\
\text { 6-11años: } 30 \mathrm{mg} \mathrm{bid}\end{array}$ \\
\hline $\begin{array}{l}\text { Mequitazina } \\
\left(\text { Primalan }^{\circledR}\right)\end{array}$ & $\begin{array}{l}\text { Comp } 10 \mathrm{mg} \\
\text { Jarabe: } 5 \mathrm{mg} / 5 \mathrm{~mL}\end{array}$ & Adultos y niños $>12 \mathrm{a}: 10 \mathrm{mg}$ & $\begin{array}{l}\text { 6-12 años: } 5 \mathrm{mg}(10 \mathrm{~mL} \text { ) } \\
\text { Dosis ponderal es de } 0.25 \mathrm{mg} / \\
\text { kg/día } \\
\text { (no excederse de } 10 \mathrm{mg} / \text { día) }\end{array}$ \\
\hline $\begin{array}{l}\text { Levocetirizina } \\
\left(\text { Xuzal }^{\circledR}\right)\end{array}$ & $\begin{array}{l}\text { Tabl } 5 \mathrm{mg} \\
\text { Gotas: } 2.5 \mathrm{mg} / 10 \text { gotas } \\
\text { Solución: } 2.5 \mathrm{mg} / 5 \mathrm{~mL}\end{array}$ & Adultos y niños > 12a: 5 mg & $\begin{array}{l}\text { 6-12m: } 1.25 \mathrm{mg}(2.5 \mathrm{~mL}) \\
\text { 1-6 años: } 1.25 \mathrm{mg}(2.5 \mathrm{~mL}) \text { bid } \\
\text { 6-12 años: } 5 \mathrm{mg}(10 \mathrm{~mL})\end{array}$ \\
\hline $\begin{array}{l}\text { Loratadina } \\
{\left(\text { Clarityne }^{\circledR}, \text { Dimegan }^{\circledR}\right.} \text {, } \\
\left.\text { Sensibit }^{\circledR}, \text { Grimeral }^{\circledR}\right)\end{array}$ & $\begin{array}{l}\text { Tabl } 10 \mathrm{mg} \\
\text { Jarabe: } 5 \mathrm{mg} / 5 \mathrm{~mL} \\
\text { Solución pediátrica: } 5 \mathrm{mg} / 5 \mathrm{~mL}\end{array}$ & Adultos y niños > 12a: 10 mg & $\begin{array}{l}\text { 1-2 años: } 2.5 \mathrm{mg}(2.5 \mathrm{~mL}) \\
\text { 2-12 años: } 5 \mathrm{mg}(5 \mathrm{~mL}) \\
\text { Niños > } 30 \mathrm{~kg}: 10 \mathrm{mg}(10 \mathrm{~mL})\end{array}$ \\
\hline $\begin{array}{l}\text { Rupatadina } \\
\left(\text { Repafet }^{\circledR}\right)\end{array}$ & Comp 10 mg & Adultos y niños > 12a: $10 \mathrm{mg}$ & $X$ \\
\hline $\begin{array}{l}\text { Astemizol** } \\
\text { (Astesen }^{\circledast} \text { ) }\end{array}$ & $\begin{array}{l}\text { Comp } 10 \mathrm{mg} \\
\text { Suspensión: } 10 \mathrm{mg} / 5 \mathrm{~mL}\end{array}$ & Adultos y niños > 12a: $10 \mathrm{mg}$ & $\begin{array}{l}\text { 2-6 años: } 1 \mathrm{~mL} / 10 \mathrm{~kg} \text { de peso } \\
\text { OD } \\
\text { 6-12a: } 1 / 2 \text { comp OD }\end{array}$ \\
\hline
\end{tabular}

* La eficacia y seguridad del clorhidrato de fexofenadina no se ha establecido en niños menores de dos años de edad con rinitis alérgica y menores de seis meses de edad con urticaria idiopática crónica.

** Con administración de 20-30 mg/día se ha reportado: paro cardiaco irreversible, prolongación del segmento QT, taquicardia ventricular polimórfica y otras arritmias ventriculares.

Fuente: Información para prescribir de los productos en México, 2013-14.

un antihistamínico $\mathrm{H} 1$ se fija a los receptores cerebrales. ${ }^{48}$ Esta medida muestra buena correlación con el grado de deterioro proporcional en el estado de alerta a causa de antihistamínicos $\mathrm{H} 1$ orales. ${ }^{49}$ Puede ser una medida objetiva para comparar la afectación del estado de alerta entre antihistamínicos $\mathrm{H} 1 .{ }^{16}$ Los antihistamínicos con ocupación de receptores (RO por sus siglas en inglés) menor a 20\% en tomografía por emisión de positrones se consideran no sedantes..$^{50} \mathrm{El}$ Cuadro 5 muestra el desempeño de todos los antihistamínicos $\mathrm{H}_{1}$ que se han probado con esta técnica hasta la fecha. ${ }^{50-52}$

Algunos estudios posmercadotecnia de vigilancia medicamentosa encontraron que el efecto 
Cuadro 5. Antihistamínicos $\mathrm{H}_{1}$ y su penetración en el sistema nervioso central: porcentaje de ocupación de receptores cerebrales

\begin{tabular}{|c|c|c|c|}
\hline Antihistamínico & Dosis & Sujetos estudiados & $\begin{array}{l}\text { Porcentaje de ocupación de } \\
\text { receptores (desviación estándar) }\end{array}$ \\
\hline \multicolumn{4}{|c|}{ Alto grado de sedación } \\
\hline d-clorfeniramina & $5 \mathrm{mg}, \mathrm{IV}$ & & 84.5 \\
\hline Ketotifeno & $1 \mathrm{mg}, \mathrm{VO}$ & & 77 \\
\hline Hidroxizina & $30 \mathrm{mg}, \mathrm{VO}$ & & 71 \\
\hline Difenidramina & $30 \mathrm{mg}, \mathrm{VO}$ & & 55.5 \\
\hline d-clorfeniramina & $2 \mathrm{mg}, \mathrm{VO}, \mathrm{DU}$ & Adultos, rinitis alérgica & $53(33)$ \\
\hline \multicolumn{4}{|c|}{ Medianamente sedante } \\
\hline Oxatomida & $30 \mathrm{mg}, \mathrm{VO}$ & & 41 \\
\hline Astemizol & $10 \mathrm{mg}, \mathrm{VO}$ & & 29 \\
\hline Cetirizina & $20 \mathrm{mg}, \mathrm{VO}$ & & 24 \\
\hline Mequitazina & $3 \mathrm{mg}, \mathrm{VO}$ & & 22 \\
\hline Azelastina & $1 \mathrm{mg}, \mathrm{VO}$ & & 20.5 \\
\hline \multicolumn{4}{|c|}{ Bajo grado de sedación } \\
\hline Bepotasina & $10 \mathrm{mg}, \mathrm{VO}$ & & 14.5 \\
\hline Olopatadina & $5 \mathrm{mg}, \mathrm{VO}$ & & 14 \\
\hline Cetirizina & $10 \mathrm{mg}, \mathrm{VO}$ & & 13.5 \\
\hline Terfenadina & $60 \mathrm{mg}, \mathrm{VO}$ & & 12 \\
\hline Loratadina & $10 \mathrm{mg}, \mathrm{VO}, \mathrm{DU}$ & Adultos, rinitis alérgica & $12(19)$ \\
\hline Ebastina & 10 mg, vO & & 10 \\
\hline Levocetirizina & $5 \mathrm{mg}, \mathrm{VO}$ & & 8 \\
\hline Epinastina & $20 \mathrm{mg}, \mathrm{VO}$ & & 8 \\
\hline Bilastina & $20 \mathrm{mg}, \mathrm{VO}$ & & -3.92 \\
\hline Fexofenadina & $120 \mathrm{mg}, \mathrm{VO}$ & & 2 \\
\hline
\end{tabular}

Antihistamínicos nuevos que cumplen con los otros criterios para ser considerados no sedantes, aunque no se realizaron estudios de tomografía por emisión de positrones en humanos: desloratadina $5 \mathrm{mg}$, rupatadina $10 \mathrm{mg}$.

Adaptado de las referencias 50 a 52.

sedante de cetirizina superó el de fexofenadina, loratadina ${ }^{53}$ y bilastina. ${ }^{17}$

Con respecto a la seguridad, no se observó afectación del tiempo de reacción en pruebas de manejo-con-frenar con fexofenadina $180 \mathrm{mg}$, ni combinada con alcohol (un consumo) ${ }^{21}$ o rupatadina $10 \mathrm{mg}$ con alcohol o bilastina 20 y $40 \mathrm{mg}$ o fexofenadina $120 \mathrm{mg}^{18}{ }^{18}$ o mizolastina $10 \mathrm{mg}^{54}$ junto con alcohol. Sí se observó alteración de la velocidad de reacción al combinar un consumo de alcohol con cetirizina de $10 \mathrm{mg}$ o con doble dosis de rupatadina o mizolastina $-20 \mathrm{mg}-.^{19,54}$ En cuanto a la coadministración de antihistamínicos con antidepresivos, la administración concomitante de bilastina 20 mg y lorazepam
3 mg durante ocho días no potenció los efectos depresores del sistema nervioso central causados por lorazepam. ${ }^{55}$

En 2003 entre expertos se intentó consensar parámetros para poder clasificar a un antihistamínico como no sedante. ${ }^{56}$ CONGA (Consensus Group of New Generation of Antihistamines) estableció los tres parámetros que deben estudiarse:

1. Incidencia de somnolencia subjetiva.

2. Funciones objetivas cognitivas y psicomotoras.

3. Medición de ocupación de receptores cerebrales $\mathrm{H} 1$ mediante tomografía por 
emisión de positrones (PET-H1RO) con doxepina radiomarcada. ${ }^{11}$

Se consideran antihistamínicos sedantes los que provocan alteración en los incisos 1 y 2 y que tengan un PET-H1RO mayor a 50\%. Los antihistamínicos con alteración leve en los incisos 1 y 2 y PET-H1RO entre $20-50 \%$ se consideran poco sedantes y sólo los antihistamínicos $\mathrm{H} 1$ que no alteran los incisos 1 ni 2 y que tengan PET$\mathrm{H} 1 \mathrm{RO}$ menor a $20 \%$ realmente se consideran no sedantes (Cuadro 5).

Conclusión. Existe importante diferencia entre los antihistamínicos en sus efectos en el sistema nervioso central. Es importante elegir un antihistamínico no sedante o poco sedante.

\section{Antihistamínicos orales $\mathrm{H} 2$ en el tratamiento de la urticaria}

La mayor parte de los estudios que mostraron eficacia de un antihistamínico $\mathrm{H} 2$ agregado a un antihistamínico $\mathrm{H} 1$ para el control de la urticaria crónica se realizaron con cimetidina. ${ }^{57,58}$ En este aspecto los resultados con ranitidina o famotidina como cotratamiento con el antihistamínico $\mathrm{H} 1$ fueron contradictorios. . $^{59,60}$ Probablemente el aparente efecto benéfico de cimetidina como cotratamiento se debe a su potente efecto inhibitorio en las enzimas hepáticas (las isoenzimas del citocromo P450), aumentando así las concentraciones plasmáticas del antihistamínico H1. ${ }^{61,62}$ En esta misma línea de pensamientos, un metanálisis Cochrane muy reciente acerca de la eficacia de antihistamínicos H2 como cotratamiento en la urticaria crónica concluyó que carecemos actualmente de evidencia sólida para recomendar este tipo de tratamiento. ${ }^{63}$ En consecuencia, no existe en este momento evidencia clara de un efecto benéfico de un antihistamínico $\mathrm{H} 2$ combinado con el tratamiento recomendado de un antihistamínico H1 de segunda generación.
Conclusión. No existe evidencia que justifique recomendar la administración de un antihistamínico $\mathrm{H} 2$ en combinación con un antihistamínico $\mathrm{H} 1$ para mejorar el control de la urticaria.

\section{Indicaciones y seguridad de los}

antihistamínicos durante el embarazo

Los antihistamínicos $\mathrm{H} 1$ son frecuentemente prescritos a mujeres en edad reproductiva y embarazadas, especialmente para el tratamiento del prurito que acompaña diversas afecciones, como ciertas dermatosis propias del embarazo, urticaria, dermatitis atópica, infecciones, reacciones a fármacos y enfermedades sistémicas. También están indicados para el tratamiento de rinitis alérgica, náuseas y vómitos, mareo de locomoción, vértigo e insomnio. ${ }^{64}$ Las enfermedades alérgicas afectan 20 a 30\% de las mujeres en edad reproductiva, por lo que constituyen las enfermedades más comunes en el embarazo. ${ }^{65}$

Los antihistamínicos $\mathrm{H}_{1}$ están entre los fármacos prescritos con más frecuencia en el embarazo. ${ }^{66}$ Por ejemplo, la loratadina fue aprobada para venta libre (OTC) en Estados Unidos en diciembre de 2002 y la prevalencia de administración durante el embarazo aumentó de alrededor de $2 \%$ en $1998-1999$ a casi $5 \%$ en $2008-2009 .{ }^{67,68}$ Durante ese periodo casi $14 \%$ de las madres reportaron el consumo de al menos un antihistamínico durante el primer trimestre del embarazo, ${ }^{68}$ lo que significa que medio millón de niños nacidos cada año han sido expuestos a antihistamínicos in utero temprano en el embarazo.

En el pasado se reportaron asociaciones entre la administración de antihistamínicos durante el embarazo y ciertas malformaciones congénitas, msmas que se resumen en el Cuadro 6.

Sin embargo, la mayor parte de los estudios que han investigado fármacos específicos 
Cuadro 6. Malformaciones congénitas asociadas con la administración de antihistamínicos

$\begin{array}{ll}\text { Antihistamínico } & \text { Malformaciones } \\ \text { Difenhidramina } & \begin{array}{c}\text { Paladar hendido, labio leporino, defectos del tubo neural, espina bífida, defectos de las extremidades, } \\ \text { onfalocele }\end{array} \\ \text { Clorfeniramina } & \begin{array}{l}\text { Defectos oculares y auriculares, espina bífida, labio leporino, paladar hendido } \\ \text { Hidroxizina }\end{array} \\ \text { Paladar hendido } \\ \text { Doxilamina } & \begin{array}{l}\text { Hendiduras orales, estenosis pilórica, síndrome de corazón izquierdo hipoplásico, espina bífida, defectos } \\ \text { del tubo neural }\end{array} \\ \text { Loratadina } & \text { Hipospadias }\end{array}$

en relación con defectos específicos no han identificado asociaciones entre el consumo materno de antihistamínicos y defectos mayores. ${ }^{68}$ Estos resultados se confirmaron en un estudio epidemiológico reciente que comparó la exposición a antihistamínicos en el primer trimestre del embarazo entre 13,127 niños con malformaciones y 6,982 controles sin malformaciones. En esta revisión no se pudo replicar ninguna de las asociaciones reportadas entre antihistamínicos específicos y malformaciones congénitas mayores, ${ }^{68}$ por lo que los investigadores sugieren que muchas, si no todas, de esas asociaciones hipotéticas podrían explicarse por el azar. Estos resultados sugieren que es improbable que la exposición a antihistamínicos se asocie estrechamente con cualquier defecto congénito mayor.

\section{Antihistamínicos de primera generación}

En el pasado se propuso la administración de antihistamínicos de primera generación en el embarazo, porque éstos se prescribieron durante un periodo más prolongado y a mayor número de embarazadas, lo que resultó en mayor cantidad de información de los efectos de éstos en el embarazo. ${ }^{69,70}$ En general, se postula que la administración de antihistamínicos de primera generación en cualquier momento del embarazo no aumenta el riesgo fetal y los datos epidemiológicos sustentan su seguridad en el primer y segundo trimestres del embarazo. Además, un metanálisis que incluyó más de 200,000 participantes concluyó que no había aumento de ningún tipo de malformación congénita. ${ }^{71}$

En 1993 el Programa Nacional de Educación y Prevención del Asma (NAEPP) recomendó los antihistamínicos de primera generación clorfeniramina y tripelenamina como los antihistamínicos de elección durante el embarazo, con base en la duración de su administración y los datos de estudios en animales y humanos. ${ }^{72}$ Otras organizaciones también habían recomendado clorfeniramina y tripelenamina como los antihistamínicos de primera elección en embarazadas. ${ }^{73}$

\section{Antihistamínicos de segunda generación}

Los lineamientos más actualizados, como ARIA (Rinitis Alérgica y su Impacto en el Asma) y los de urticaria, propuestos por la Academia Europea de Alergología e Inmunología Clínica y la Organización Mundial de Alergia (EAACI/GA2LEN/ EDF/WAO) recomiendan los antihistamínicos de segunda generación para las embarazadas. Esto se fundamenta en su mayor seguridad, en comparación con los antihistamínicos $\mathrm{H} 1$ orales de primera generación. ${ }^{2,74}$ Mientras el Grupo de Trabajo ARIA postula que los antihistamínicos de primera generación no deben prescribirse, el documento de urticaria recomienda administrar loratadina, desloratadina, cetirizina o levocetirzina, mientras que los antihistamínicos $\mathrm{H} 1$ orales 
de primera generación sólo estarían indicados cuando no se observa respuesta a los de segunda generación. El Cuadro 7 muestra la clasificación de la Dirección de Alimentos y Fármacos de Estados Unidos de los medicamentos de acuerdo con su seguridad en el embarazo y en qué categoría se encuentran los antihistamínicos $\mathrm{H} 1$ orales actuales.

Como puede observarse en el Cuadro 7, la mayor parte de los antihistamínicos se consideran categoría B. Debido al escaso número de estudios controlados en mujeres embarazadas, ${ }^{75}$ no pueden obtener la categoría A.

Varios estudios sustentan la seguridad de los antihistamínicos en el embarazo. Por ejemplo, en una investigación no se observaron diferencias en el resultado del embarazo de 120 mujeres expuestas a hidroxizina, 39 a cetirizina y un grupo control. ${ }^{76}$ El Registro Sueco de Nacimientos entre 1995 y 1999, que incluyó 17,766 mujeres expuestas a antihistamínicos, de las que 917 recibieron cetirizina, no demostró aumento del riesgo de malformaciones en comparación con la población general ${ }^{77}$ y estos resultados fueron confirmados en otros estudios. $^{78}$

De la fexofenadina no hay suficiente información en humanos, mientras que de loratadina, cetirizina y desloratadina se ha reportado que no existe mayor riesgo de malformaciones mayores. ${ }^{77-80}$

Conclusión. La administración de cualquier fármaco durante el primer trimestre del embarazo, incluidos los antihistamínicos, debe ser diferida

Cuadro 7. Asignación por la Dirección de Alimentos y Fármacos de Estados Unidos (FDA) de los antihistamínicos H1 orales en las categorías de medicamentos en el embarazo

\begin{tabular}{|c|c|c|}
\hline Categoría & Antihistamínico & Descripción \\
\hline A & Ninguno & $\begin{array}{l}\text { Humanos: estudios adecuados, bien controlados, en embarazadas no han demos- } \\
\text { trado aumento del riesgo de anomalías fetales en ningún trimestre del embarazo. } \\
\text { Animales: no disponible. }\end{array}$ \\
\hline \multirow[t]{3}{*}{ B } & $\begin{array}{l}\text { Primera generación: (Dex) } \\
\text { clorfeniramina, ciprohep- } \\
\text { tadina, tripelenamina }\end{array}$ & $\begin{array}{l}\text { Humanos: no hay estudios adecuados, bien controlados, en mujeres embarazadas } \\
\text { Animales: sin evidencias de daño al feto }\end{array}$ \\
\hline & & $\mathrm{o}$ \\
\hline & $\begin{array}{l}\text { Segunda generación: ce- } \\
\text { tirizina, loratadina, levo- } \\
\text { cetirizina }\end{array}$ & $\begin{array}{l}\text { Humanos: estudios adecuados, bien controlados, en mujeres embarazadas no han } \\
\text { demostrado riesgo al feto en ningún trimestre } \\
\text { Animales: los estudios han demostrado un efecto adverso }\end{array}$ \\
\hline \multirow[t]{2}{*}{$\mathrm{C}$} & $\begin{array}{l}\text { Primera generación: hi- } \\
\text { droxizina, prometazina }\end{array}$ & $\begin{array}{l}\text { Humanos: no hay estudios adecuados, bien controlados, en mujeres embarazadas } \\
\text { Animales: los estudios han demostrado un efecto adverso } \\
\text { o }\end{array}$ \\
\hline & $\begin{array}{l}\text { Segunda generación: fexo- } \\
\text { fenadina, desloratadina }\end{array}$ & $\begin{array}{l}\text { Humanos: no hay estudios adecuados, bien controlados, en mujeres embarazadas } \\
\text { Animales: no se han realizado estudios. }\end{array}$ \\
\hline $\mathrm{D}$ & Ninguno & $\begin{array}{l}\text { Humanos: estudios adecuados, bien controlados u observacionales en mujeres } \\
\text { embarazadas han demostrado un riesgo al feto. Sin embargo, los beneficios de } \\
\text { la terapia pueden superar el riesgo potencial. Por ejemplo, el fármaco puede ser } \\
\text { aceptable si se requiere para tratar una situación que pone en peligro la vida o } \\
\text { enfermedad grave contra las que fármacos más seguros no pueden administrarse } \\
\text { o son inefectivos }\end{array}$ \\
\hline $\mathrm{x}$ & Ninguno & $\begin{array}{l}\text { Estudios adecuados, bien controlados u observacionales en animales o mujeres } \\
\text { embarazadas han demostrado evidencias positivas de anomalías o riesgos fetales. } \\
\text { La administración del producto está contraindicada en mujeres embarazadas o } \\
\text { que pueden embarazarse }\end{array}$ \\
\hline
\end{tabular}


en cuanto sea posible. Los antihistamínicos de segunda generación, especialmente cetirizina y loratadina, tienen preferencia por su mayor seguridad. Se recomienda administrar las dosis más bajas que sean efectivas y discutir con la paciente los riesgos y posibles beneficios de la medicación.

\section{Antihistamínicos y lactancia}

Se ha determinado que los antihistamínicos de primera generación y también loratadina, fexofenadina y desloratadina son secretados en la leche en cantidades mínimas..$^{70,81}$ Por tanto, es improbable que éstos tengan efectos adversos en

Cuadro 8. Antihistamínicos y su recomendación en el embarazo y la lactancia

\begin{tabular}{|c|c|c|c|}
\hline & Embarazo & Lactancia & $\begin{array}{l}\text { Riesgo según } \\
\text { APILAM }\end{array}$ \\
\hline Cetirizina & $\begin{array}{l}\text { Se debe tener precaución cuando se prescribe } \\
\text { cetirizina a mujeres embarazadas }\end{array}$ & $\begin{array}{l}\text { Cetirizina se elimina en la leche materna. Se } \\
\text { debe tener precaución cuando se prescribe } \\
\text { cetirizina a mujeres en periodo de lactancia }\end{array}$ & 0 \\
\hline Des-loratadina & $\begin{array}{l}\text { No debe administrarse durante el embarazo } \\
\text { a menos que se establezca formalmente la } \\
\text { relación beneficio-riesgo }\end{array}$ & $\begin{array}{l}\text { Se excreta a través de la leche materna. Se de- } \\
\text { berá decidir suspender la lactancia materna } \\
\text { o desloratadina }\end{array}$ & 0 \\
\hline Loratadina & $\begin{array}{l}\text { Se deberá prescribir durante el embarazo } \\
\text { en los casos en los que los beneficios po- } \\
\text { tenciales superen con claridad los riesgos } \\
\text { potenciales }\end{array}$ & $\begin{array}{l}\text { Se excreta a través de la leche materna. Se } \\
\text { deberá decidir suspender la lactancia ma- } \\
\text { terna o loratadina }\end{array}$ & 0 \\
\hline Bilastina & $\begin{array}{l}\text { Embarazo: no hay datos o éstos son limitados. } \\
\text { Los estudios en animales no sugieren efectos } \\
\text { perjudiciales para la reproducción, el parto } \\
\text { o el desarrollo posnatal. Como medida de } \\
\text { precaución, es preferible evitar bilastina } \\
\text { durante el embarazo }\end{array}$ & $\begin{array}{l}\text { Lactancia: se desconoce si bilastina se ex- } \\
\text { creta en la leche materna. Se debe decidir } \\
\text { si es preferible continuar o interrumpir la } \\
\text { lactancia o el tratamiento con bilastina tras } \\
\text { considerar el beneficio de la lactancia para } \\
\text { el niño y el beneficio del tratamiento para } \\
\text { la madre }\end{array}$ & 1 \\
\hline Ebastina & & & 1 \\
\hline Epinastina & $\begin{array}{l}\text { Siguiendo normas internacionales, no se } \\
\text { recomienda su administración durante el } \\
\text { embarazo ni la lactancia }\end{array}$ & $\begin{array}{l}\text { Siguiendo normas internacionales, no se } \\
\text { recomienda su administración durante el } \\
\text { embarazo ni la lactancia }\end{array}$ & 1 \\
\hline Fexo-fenadina & $\begin{array}{l}\text { No debe administrarse durante el embarazo, } \\
\text { a menos que el beneficio esperado para la } \\
\text { paciente supere cualquier posible riesgo } \\
\text { para el feto }\end{array}$ & $\begin{array}{l}\text { No debe administrarse durante la lactancia, } \\
\text { a menos que el beneficio esperado para la } \\
\text { paciente supere cualquier posible riesgo } \\
\text { para el recién nacido }\end{array}$ & 1 \\
\hline Levo-cetirizina & $\begin{array}{l}\text { No hay resultados clínicos disponibles. Los } \\
\text { estudios en animales no indican efectos } \\
\text { dañinos para la reproducción, el parto o el } \\
\text { desarrollo posnatal. Como medida de pre- } \\
\text { caución, es preferible evitar la administra- } \\
\text { ción de levocetirizina durante el embarazo }\end{array}$ & $\begin{array}{l}\text { Cetirizina es excretada en la leche materna. } \\
\text { Deben tomarse precauciones cuando se } \\
\text { prescribe a mujeres embarazadas o lactando }\end{array}$ & 1 \\
\hline Rupatadina & $\begin{array}{l}\text { No se recomienda la administración de rupa- } \\
\text { tadina durante el embarazo }\end{array}$ & $\begin{array}{l}\text { No se recomienda la administración de rupa- } \\
\text { tadina en la lactancia }\end{array}$ & 1 \\
\hline Mequi-tazina & $\begin{array}{l}\text { No se recomienda la administración de me- } \\
\text { quitazina durante el embarazo }\end{array}$ & $\begin{array}{l}\text { No se recomienda la administración de me- } \\
\text { quitazina en la lactancia }\end{array}$ & 2 \\
\hline Astemizol & $\begin{array}{l}\text { No se recomienda su administración durante } \\
\text { el embarazo, pero el médico debe valorar } \\
\text { los riesgos y beneficios }\end{array}$ & $\begin{array}{l}\text { No se recomienda su administración durante } \\
\text { la lactancia, pero el médico debe valorar los } \\
\text { riesgos y beneficios }\end{array}$ & 2 \\
\hline
\end{tabular}

Fuente: información para prescribir de los productos en México, 2013.

APILAM: Asociación para la Promoción e Investigación de la Lactancia Materna: www.e-lactancia.org 
lactantes. Sin embargo, en las guías de urticaria se inclyó una nota de precaución que indica que deben administrarse antihistamínicos de segunda generación en madres que amamantan porque los de primera generación pueden inducir sedación en el niño a través de la lactancia materna. ${ }^{2}$ El Cuadro 8 contiene los textos oficiales autorizados de los antihistamínicos en México en la información para prescribir. En la última columna se agrega la calificación de riesgo según la Asociación para la Promoción e Investigación de la Lactancia Materna (APILAM); generalmente se considera que no existe contraindicación para seguir amamantando para las mamás que ingieren los medicamentos con calificación APILAM 0 o 1.

\section{CONCLUSIÓN}

La urticaria es una de las enfermedades que aqueja a un gran número de pacientes en alguna etapa de su vida. La histamina representa uno de los mediadores más importantes que desencadenan los síntomas de ésta. Las células cebadas tienen gran número de receptores de histamina. Existen cuatro tipos de receptores de histamina ( $\mathrm{H} 1 \mathrm{a} \mathrm{H} 4)$. Los de tipo 1 se encuentran en: sistema nervioso central, músculo liso, respiratorio, gastrointestinal, cardiovascular y epitelial. Al activarse éstos ocasionan prurito, eritema, edema, aumento de la inflamación y broncoconstricción. Los receptores de histamina son estructuras transmembrana que continuamente cambian de una configuración (activa) a otra (no activa). Los antihistamínicos son agonistas inversos porque estabilizan el estado no activo del receptor. Existen dos grupos de antihistamínicos H1 orales: los de primera y los de segunda generación. Estos últimos tienen menos reacciones adversas que los primeros, lo que los hace considerablemente seguros. Para el tratamiento de la urticaria aguda o crónica se recomienda como primera elección un antihistamínico H1 oral de segunda generación. Las guías nacionales e internacionales recientes sugieren que en caso necesario se pueden dar dosis hasta cuatro veces mayores de la dosis estándar para lograr el control de los síntomas, pero esto sólo se puede hacer con los antihistamínicos $\mathrm{H} 1$ orales de segunda generación con mayor margen de seguridad y de preferencia con los que demostraron mejor eficacia para el control de la urticaria al aumentar su dosis. La administración de antihistamínicos $\mathrm{H} 1$ orales de primera generación en el tratamiento de urticaria crónica ya no es recomendable y, en caso de prescribirlos, será por tiempo corto, en dosis bajas nocturnas.

\section{REFERENCIAS}

1. Brozek JL, Bousquet J, Baena-Cagnani CE, Bonini S, et al. Allergic Rhinitis and its Impact on Asthma (ARIA) guidelines: 2010 revision. J Allergy Clin Immunol 2010;126:466-476.

2. Zuberbier T, Aberer W, Asero R, Bindslev-Jensen $C$, et al. The EAACI/GA LEN/EDF/WAO Guideline for the definition, classification, diagnosis, and management of urticaria: the 2013 revision and update. Allergy 2014;69:868-887.

3. Larenas-Linnemann D, Mayorga-Butron JL, Sánchez-González A, Ramírez-García A, et al. ARIA Mexico 2014. Adaptation of the Clinical Practice Guide ARIA 2010 for Mexico. Methodology ADAPTE. Rev Alerg Mex 2014;61:3-116.

4. Larenas-Linnemann D, Medina-Ávalos MA, Ortega-Martell $J A$, Beirana-Palencia AM, et al. Mexican guidelines on the diagnosis and treatment of urticaria. Rev Alerg Mex 2014;61:118-193.

5. ADAPTE Collaboration. The ADAPTE Manual and Resource Toolkit for Guideline Adaptation. Version 2.02010 [cited 2014 11th of february]. Disponible en: http://www.g-i-n-net

6. Simons FER, Akdis CA. Histamine and $\mathrm{H} 1$-antihistamines. In: Adkinson NJ, Bochner BS, Busse WW, Holgate ST, Lemanske RF, Simons FER, editors. Middleton's allergy: principles and practice: Mosby (an affiliate of Elsevier Science); 2009;1517-1548.

7. Frei $R$, Ferstl $R$, Konieczna $P$, Ziegler $M$, et al. Histamine receptor 2 modifies dendritic cell responses to microbial ligands. J Allergy Clin Immunol 2013;132:194-204.

8. Tiligada E, Zampeli E, Sander K, Stark H. Histamine H3 and $\mathrm{H} 4$ receptors as novel drug targets. Expert Opin Investig Drugs 2009;18:1519-1531.

9. Zampeli $\mathrm{E}$, Tiligada $\mathrm{E}$. The role of histamine $\mathrm{H} 4$ receptor in immune and inflammatory disorders. Br J Pharmacol 2009;157:24-33.

10. Gutzmer R, Gschwandtner M, Rossbach K, Mommert S, et al. Pathogenetic and therapeutic implications of the 
histamine $\mathrm{H} 4$ receptor in inflammatory skin diseases and pruritus. Front Biosci (School Ed) 2011;3:985-994.

11. Church MK, Maurer M, Simons FE, Bindslev-Jensen C, et al. Risk of first-generation $\mathrm{H}(1)$-antihistamines: a GA(2)LEN position paper. Allergy 2010;65:459-466.

12. Lee EE, Maibach HI. Treatment of urticaria. An evidencebased evaluation of antihistamines. Am J Clin Dermatol 2001;2:27-32.

13. Group C. CONSORT transparent reporting of trials 2013 [cited 2013 22nd of November]. Disponible en: http:// www.consort-statement.org/.

14. Brozek JL, AkI EA, Alonso-Coello P, Lang D, et al. Grading quality of evidence and strength of recommendations in clinical practice guidelines. Part 1 of 3 . An overview of the GRADE approach and grading quality of evidence about interventions. Allergy 2009;64:669-677.

15. Alsamarai AM, Hasan AA, Alobaidi AH. Evaluation of different combined regimens in the treatment of cholinergic urticaria. World Allergy Organ J 2012;5:88-93.

16. Simons FE, Simons KJ. Histamine and $\mathrm{H} 1$-antihistamines: celebrating a century of progress. J Allergy Clin Immunol 2011;128:1139-1150.

17. Scaglione F. Safety profile of bilastine: 2 nd generation H1antihistamines. Eur Rev Med Pharmacol Sci 2012;16:19992005.

18. Tashiro M, Horikawa E, Mochizuki H, Sakurada $\mathrm{Y}$, et al. Effects of fexofenadine and hydroxyzine on brake reaction time during car-driving with cellular phone use. Hum Psychopharmacol 2005;20:501-509.

19. Barbanoj MJ, García-Gea C, Antonijoan R, Izquierdo I, et al. Evaluation of the cognitive, psychomotor and pharmacokinetic profiles of rupatadine, hydroxyzine and cetirizine, in combination with alcohol, in healthy volunteers. Hum Psychopharmacol 2006;21:13-26.

20. Sen A, Akin A, Craft KJ, Canfield DV, Chaturvedi AK. Firstgeneration $\mathrm{H} 1$ antihistamines found in pilot fatalities of civil aviation accidents, 1990-2005. Aviat Space Environ Med 2007;78:514-522.

21. Ridout F, Shamsi Z, Meadows R, Johnson S, Hindmarch I. A single-center, randomized, double-blind, placebo-controlled, crossover investigation of the effects of fexofenadine hydrochloride $180 \mathrm{mg}$ alone and with alcohol, with hydroxyzine hydrochloride $50 \mathrm{mg}$ as a positive internal control, on aspects of cognitive and psychomotor function related to driving a car. Clin Ther2003;25:1518-1538.

22. Vuurman EF, van Veggel $L M$, Uiterwijk MM, Leutner $D$, O'Hanlon JF. Seasonal allergic rhinitis and antihistamine effects on children's learning. Ann Allergy 1993;71:121-126.

23. Walker $S$, Khan-Wasti S, Fletcher $M$, Cullinan $P$, et al. Seasonal allergic rhinitis is associated with a detrimental effect on examination performance in United Kingdom teenagers: case-control study. J Allergy Clin Immunol 2007;120:381-387.

24. Boyle J, Eriksson M, Stanley N, Fujita T, Kumagi Y. Allergy medication in Japanese volunteers: treatment effect of single doses on nocturnal sleep architecture and next day residual effects. Curr Med Res Opin 2006;22:1343-1351.

25. Zhang D, Tashiro M, Shibuya K, Okamura N, et al. Next-day residual sedative effect after nighttime administration of an over-the-counter antihistamine sleep aid, diphenhydramine, measured by positron emission tomography. J Clin Psychopharmacol 2010;30:694-701.

26. Ikeda-Sagara M, Ozaki T, Shahid M, Morioka E, et al. Induction of prolonged, continuous slow-wave sleep by blocking cerebral $\mathrm{H}_{1}$ histamine receptors in rats. Br J Pharmacol 2012;165:167-182.

27. Staevska M, Gugutkova M, Lazarova C, Kralimarkova T, et al. Night-time sedating $\mathrm{H} 1$-antihistamine increases daytime somnolence but not treatment efficacy in chronic spontaneous urticaria: a randomized controlled trial. $\mathrm{Br} \mathrm{J}$ Dermatol 2014;171:148-154.

28. Sánchez-Borges M, Asero R, Ansotegui IJ, Baiardini I, et al. Diagnosis and treatment of urticaria and angioedema: a worldwide perspective. World Allergy Organ J 2012;5:125147.

29. Zuberbier T, Asero R, Bindslev-Jensen C, Walter Canonica G, et al. EAACl/GA(2)LEN/EDF/WAO guideline: management of urticaria. Allergy 2009;64:1427-1443.

30. Powell RJ, Du Toit GL, Siddique N, Leech SC, et al. BSACI guidelines for the management of chronic urticaria and angio-oedema. Clin Exp Allergy 2007;37:631-650.

31. Handa S, Dogra S, Kumar B. Comparative efficacy of cetirizine and fexofenadine in the treatment of chronic idiopathic urticaria. J Dermatolog Treat 2004;15:55-57.

32. Potter PC, Kapp A, Maurer M, Guillet G, et al. Comparison of the efficacy of levocetirizine $5 \mathrm{mg}$ and desloratadine $5 \mathrm{mg}$ in chronic idiopathic urticaria patients. Allergy 2009;64:596-604.

33. Zuberbier T, Oanta A, Bogacka E, Medina I, et al. Comparison of the efficacy and safety of bilastine $20 \mathrm{mg}$ vs levocetirizine $5 \mathrm{mg}$ for the treatment of chronic idiopathic urticaria: a multi-centre, double-blind, randomized, placebo-controlled study. Allergy 2010;65:516-528.

34. Church MK. Comparative inhibition by bilastine and cetirizine of histamine-induced wheal and flare responses in humans. Inflamm Res 2011;60:1107-1112.

35. Clough GF, Boutsiouki P, Church MK. Comparison of the effects of levocetirizine and loratadine on histamineinduced wheal, flare, and itch in human skin. Allergy 2001;56:985-988.

36. Grant JA, Riethuisen JM, Moulaert B, DeVos C. A doubleblind, randomized, single-dose, crossover comparison of levocetirizine with ebastine, fexofenadine, loratadine, mizolastine, and placebo: suppression of histamine-induced wheal-and-flare response during 24 hours in healthy male subjects. Ann Allergy Asthma Immunol 2002;88:190-197.

37. Popov TA, Dumitrascu D, Bachvarova A, Bocsan C, et al. A comparison of levocetirizine and desloratadine in the histamine-induced wheal and flare response in human skin in vivo. Inflamm Res 2006;55:241-244. 
38. Hampel F, Ratner P, Haeusler JM. Safety and tolerability of levocetirizine dihydrochloride in infants and children with allergic rhinitis or chronic urticaria. Allergy Asthma Proc 2010;31:290-295

39. Sánchez-Borges M, Caballero-Fonseca F, Capriles-Hulett A. Treatment of recalcitrant chronic urticaria with nonsedating antihistamines: is there evidence for updosing? J Investig Allergol Clin Immunol 2013;23:141-144.

40. Zuberbier T, Munzberger C, Haustein U, Trippas E, et al. Double-blind crossover study of high-dose cetirizine in cholinergic urticaria. Dermatology 1996;193:324-327.

41. Godse KV. Ebastine in chronic spontaneous urticaria in higher doses. Indian J Dermatol 2011;56:597-598.

42. Krause K, Spohr A, Zuberbier T, Church MK, Maurer M. Up-dosing with bilastine results in improved effectiveness in cold contact urticaria. Allergy 2013;68:921-928.

43. Staevska M, Popov TA, Kralimarkova T, Lazarova C, et al. The effectiveness of levocetirizine and desloratadine in up to 4 times conventional doses in difficult-to-treat urticaria. J Allergy Clin Immunol 2010;125:676-682.

44. Siebenhaar F, Degener F, Zuberbier T, Martus P, Maurer M. High-dose desloratadine decreases wheal volume and improves cold provocation thresholds compared with standard-dose treatment in patients with acquired cold urticaria: a randomized, placebo-controlled, crossover study. J Allergy Clin Immunol 2009;123:672-679.

45. Church MK. Efficacy and tolerability of rupatadine at four times the recommended dose against histamine- and platelet-activating factor-induced flare responses and ex vivo platelet aggregation in healthy males. Br J Dermatol 2010;163:1330-1332.

46. Gimenez-Arnau A, Izquierdo I, Maurer M. The use of a responder analysis to identify clinically meaningful differences in chronic urticaria patients following placebo-controlled treatment with rupatadine 10 and 20 mg. J Eur Acad Dermatol Venereol 2009;23:1088-1091.

47. Kavosh ER, Khan DA. Second-generation H1-antihistamines in chronic urticaria: an evidence-based review. Am J Clin Dermatol 2011;12:361-376.

48. Yanai K, Ryu JH, Watanabe T, Iwata R, et al. Histamine $\mathrm{H} 1$ receptor occupancy in human brains after single oral doses of histamine $\mathrm{H} 1$ antagonists measured by positron emission tomography. Br J Pharmacol 1995;116:1649-1655.

49. McDonald K, Trick L, Boyle J. Sedation and antihistamines: an update. Review of inter-drug differences using proportional impairment ratios. Hum Psychopharmacol 2008;23:555-570.

50. Farre M, Pérez-Mañá C, Papaseit E, Menoyo E, et al. Bilastine vs hydroxyzine: occupation of brain histamine $\mathrm{H} 1$ -receptors evaluated by positron emission tomography in healthy volunteers. Br J Clin Pharmacol 2014.

51. Yanai K, Zhang D, Tashiro M, Yoshikawa T, et al. Positron emission tomography evaluation of sedative properties of antihistamines. Expert Opin Drug Saf 2011;10:613-622.
52. Hiraoka K, Tashiro M, Grobosch T, Maurer M, et al. Brain histamine $\mathrm{H} 1$ receptor occupancy measured by PET after oral administration of levocetirizine, a non-sedating antihistamine. Expert Opin Drug Saf 2014:1-8.

53. Curran MP, Scott LJ, Perry CM. Cetirizine: a review of its use in allergic disorders. Drugs 2004;64:523-561.

54. Vuurman EF, Uiterwijk MM, Rosenzweig P, O'Hanlon JF. Effects of mizolastine and clemastine on actual driving and psychomotor performance in healthy volunteers. Eur J Clin Pharmacol 1994;47:253-259.

55. Montoro J, Mullol J, Dávila I, Ferrer M, et al. Bilastine and the central nervous system. J Investig Allergol Clin Immunol 2011;21:9-15.

56. Holgate ST, Canonica GW, Simons FE, Taglialatela M, et al. Consensus Group on New-Generation Antihistamines (CONGA): present status and recommendations. Clin Exp Allergy 2003;33:1305-1324.

57. Bleehen SS, Thomas SE, Greaves MW, Newton J, et al. Cimetidine and chlorpheniramine in the treatment of chronic idiopathic urticaria: a multi-centre randomized double-blind study. Br J Dermatol 1987;117:81-88.

58. Monroe EW, Cohen SH, Kalbfleisch J, Schulz Cl. Combined $\mathrm{H} 1$ and $\mathrm{H} 2$ antihistamine therapy in chronic urticaria. Arch Dermatol 1981;117:404-407.

59. Paul E, Bödeker RH. Treatment of chronic urticaria with terfenadine and ranitidine. A randomized double-blind study in 45 patients. Eur J Clin Pharmacol 1986;31:277-280.

60. Sharpe GR, Shuster S. In dermographic urticaria $\mathrm{H} 2$ receptor antagonists have a small but therapeutically irrelevant additional effect compared with $\mathrm{H} 1$ antagonists alone. $\mathrm{Br}$ J Dermatol 1993;129:575-579.

61. Salo OP, Kauppinen K, Männistö PT. Cimetidine increases the plasma concentration of hydroxyzine. Acta Derm Venereol 1986;66:349-350.

62. Simons FE, Sussman GL, Simons KJ. Effect of the H2antagonist cimetidine on the pharmacokinetics and pharmacodynamics of the $\mathrm{H} 1$-antagonists hydroxyzine and cetirizine in patients with chronic urticaria. J Allergy Clin Immunol 1995;95:685-693.

63. Fedorowicz Z, van Zuuren EJ, Hu N. Histamine H2-receptor antagonists for urticaria. Cochrane Database Syst Rev 2012;3:CD008596.

64. Hardman J, Limbird L, Goodman-Gilman A. Goodman and Gilman's The Pharmacological Basis of Therapeutics. $10^{\text {th }}$ ed. New York: McGraw-Hill, 2001.

65. Buhimschi CS, Weiner CP. Medications in pregnancy and lactation: Part 2. Drugs with minimal or unknown human teratogenic effect. Obstet Gynecol 2009;113:417-432.

66. Werler MM, Mitchell AA, Hernandez-Diaz S, Honein MA. Use of over-the-counter medications during pregnancy. Am J Obstet Gynecol 2005;193:771-777.

67. Sullivan PW, Nair KV, Patel BV. The effect of the Rx-to-OTC switch of loratadine and changes in prescription drug benefits on utilization and cost of therapy. Am J Manag Care 2005;11:374-382. 
68. Li Q, Mitchell AA, Werler MM, Yau WP, Hernandez-Diaz S. Antihistamine use in early pregnancy and risk of birth defects. J Allergy Clin Immunol Pract 2013;1:666-674.

69. Gilbert C, Mazzotta P, Loebstein R, Koren G. Fetal safety of drugs used in the treatment of allergic rhinitis: a critical review. Drug Saf 2005;28:707-719.

70. So M, Bozzo P, Inoue M, Einarson A. Safety of antihistamines during pregnancy and lactation. Can Fam Physician Med Fam Can 2010;56:427-429.

71. Seto A, Einarson T, Koren G. Pregnancy outcome following first trimester exposure to antihistamines: meta-analysis. Am J Perinatol 1997;14:119-124.

72. NAEPP Report of the Working Group on Asthma and Pregnancy: management of asthma during pregnancy. In: US Department of Health and Human Services; National Institutes of Health; National Heart L, and Blood Institute, editor. Bethesda, MD: NIH Publication No. 93-3279 1993.

73. The use of newer asthma and allergy medications during pregnancy. The American College of Obstetricians and Gynecologists (ACOG) and The American College of Allergy, Asthma and Immunology (ACAAI). Ann Allergy Asthma Immunol 2000;84:475-480.

74. Bousquet J, Van Cauwenberge P, Khaltaev N. Allergic rhinitis and its impact on asthma. J Allergy Clin Immunol 2001;108:147-334.
75. Briggs G, Freeman R, Yaffe SJ. Drugs in pregnancy and lactation. $7^{\text {th }}$ ed. Philadelphia: Lippincott Williams \& Wilkins, 2002.

76. Einarson A, Bailey B, Jung G, Spizzirri D, Baillie M, Koren G. Prospective controlled study of hydroxyzine and cetirizine in pregnancy. Ann Allergy Asthma Immunol 1997;78:183-186.

77. Kallen B. Use of antihistamine drugs in early pregnancy and delivery outcome. The Journal of Maternal-fetal \& Neonatal Medicine: the official journal of the European Association of Perinatal Medicine, the Federation of Asia and Oceania Perinatal Societies, the International Society of Perinatal Obstet, 2002;11:146-152.

78. Weber-Schoendorfer C, Schaefer C. The safety of cetirizine during pregnancy. A prospective observational cohort study. Reprod Toxicol 2008;26:19-23.

79. Diav-Citrin O, Shechtman S, Aharonovich A, Moerman L, et al. Pregnancy outcome after gestational exposure to loratadine or antihistamines: a prospective controlled cohort study. J Allergy Clin Immunol 2003;111:1239-1243.

80. Moretti ME, Caprara D, Coutinho CJ, Bar-Oz B, et al. Fetal safety of loratadine use in the first trimester of pregnancy: a multicenter study. J Allergy Clin Immunol 2003;111:479-483.

81. Rindi V. La eliminazione degli antistaminici di sintesi con il latte e l'azione latto-goga di questi. Riv Ital Ginecol 1951;84:147-157

\section{INMUNOCOLOMBIA 2015}

\section{Congreso de la Asociación Latinoamericana de Inmunología (ALAI)}

Medellín, Colombia

8 al 12 de septiembre de 2015

http://www.inmunocolombia2015.com/congreso/ 